\title{
Prevalence of Acute Kidney Injury in Pediatric Patients with Congenital Heart Disease Following Open Heart Surgery
}

\author{
Marwa Zakaria ${ }^{1}$, Ali Mohamed Refat ${ }^{2}$, Naglaa Ali Khalifa ${ }^{3}$, Kamal Mohammed Abd El-Hakim*1 \\ Departments of ${ }^{1}$ Pediatrics, ${ }^{2}$ Cardiothoracic Surgery and ${ }^{3}$ Clinical Pathology, Faculty of Medicine - Zagazig \\ University, Egypt \\ *Corresponding Author: Kamal Mohammed Abd El-Hakim, Mobile: (+20)01141145844,
}

Email: kimohakim2020@gmail.com

\begin{abstract}
Background: Acute kidney injury (AKI) occurs in approximately $40 \%$ of children undergoing cardiac surgery and is a risk factor for morbidity and mortality. Such injury leads to several complications, including fluid and electrolyte disturbances.

Objective: To determine prevalence of acute kidney injury in pediatric patients with congenital heart disease following open heart surgery.

Patients and Methods: We conducted a case control study on 20 patients with congenital heart disease (10 males and 10 females) with mean age of $3.39 \pm 1.17$ years old, and a range from 1 to 5 years old. They were recruited from Pediatric Cardiothoracic Unit, Zagazig University Hospital and 20 sex and age matched healthy children worked as control group.

Results: The mean age of our patients was $3.39 \pm 1.17$ years old with a range from 1 to 5 years. $50 \%$ were males and $50 \%$ were females with no statistically significant difference between both groups regarding age and sex. about $1 / 3$ of the studied group had ASD (30\%), while $1 / 4$ of them had Fallot tetralogy (25\%), and only $15 \%$ of them had VSD, subaortic membrane and PM + VSD. The mean serum creatinine level was $0.8 \pm 0.15 \mathrm{mg} / \mathrm{dl}$, with a range from $0.22-0.9 \mathrm{mg} / \mathrm{dl} .70 \%$ of the patients had no acute kidney injury, $15 \%$ developed AKI stage 1 and $15 \%$ developed stage 2 AKI. In addition, all patients with AKI needed dialysis.

Conclusion: Present study identified that high percentage of pediatric patients with congenital heart disease following open-heart surgery developed acute kidney injury.
\end{abstract}

Keywords: Prevalence, AKI, Congenital heart disease, Cardiac surgery.

\section{INTRODUCTION}

Congenital heart malformations are one of the most prevalent birth defects that accounts for one third of children with birth defects. Its prevalence is about 8 -10 cases per 1000 births. Ventral septal defect (VSD) is the most important defect with an estimated prevalence rate about $40 \%$ of the congenital heart diseases (CHD). The majority of those defects are isolated cardiac anomalies while there is still $20 \%$ who have more than one cardiac defect (1). Surgical correction of these CHD is the GOLD STANDERED to avoid the serious unwanted implications of these lesions on patient-associated morbidity \& mortality and thus improves quality of life and life expectancy to those patients ${ }^{(2)}$.

Acute kidney injury is a common and serious complication of cardiothoracic surgery. In cardiac surgery patients, postoperative increases of serum creatinine of 20-25\% from preoperative baselines are associated with increased morbidity and mortality ${ }^{(3,4)}$. The development of acute kidney injury is one of the risk factors for negative hospital outcomes for patients who undergo cardiac surgery. Intense contemporary research has been directed toward validating other biomarkers to predict acute kidney injury earlier than is feasible with acute changes in serum creatinine. The best global index for renal function is GFR, which can be estimated using inulin clearance, (51Cr-EDTA), iohexol, serum creatinine value. However, there is a need to develop early biomarkers of acute kidney injury following cardiac surgery, where morbidity and mortality are increased by its presence ${ }^{(5)}$.

The study aimed to determine prevalence of acute kidney injury in pediatric patients with congenital heart disease following open-heart surgery.

\section{PATIENTS AND METHODS}

A) Site of the study: This study was carried out in Pediatric Cardiothoracic Unit, Zagazig University Hospital.

B) Type of study: Cross sectional comparative study. C) Sample size: Assuming that the total population size of children under open-heart surgery is 30 patients in the study period ( 6 months) and predictive value positive of Cystatin C in detection of AKI is $95 \%$, so the sample size is 20 patients and 20 healthy matched controls.

D) Target population: Patients diagnosed with congenital heart diseases (CH D) in Pediatric Department, Zagazig University Hospital (ZUH) who will undergo open heart for correction of the defect at cardiothoracic surgery department.

\section{Inclusion Criteria:}

- Age $>2$ years and $<18$ years old 
- Children diagnosed with congenital heart diseases and undergoing cardiopulmonary bypass (CPB) at our center for surgical correction or palliation of congenital heart lesions.

- Approval to sign an informed written consent. Exclusion criteria:

- Age $<2$ years \& $>18$ years old.

- pre-existing renal insufficiency (based on age-adjusted normal ranges for $\mathrm{SCr}$ ),

- Diabetes mellitus

- Peripheral vascular disease

- Use of nephrotoxic agents up to 1 week before or during the study period

- Urgent cases

- Refusal of the parents to sign an informed written consent.

\section{Ethical approval:}

The study was approved from Institutional Review Board, Faculty of Medicine, Zagazig University. Approval of the study was obtained from Pediatrics Clinical Pathology and Cardiothoracic Surgery Departments of Zagazig University. An informed written consent was taken from patients and/or their guardians.

\section{All patients were subjected to:}

(1) Full history taking.

(2) Complete clinical examination.

(3) Routine laboratory investigations including liver functions tests, serum creatinine level preoperative and at 6 hours and 24 hours postoperative and echo (preoperative and postoperative).

\section{Statistical analysis:}

The collected data were analyzed by computer using Statistical Package of Social Services version 24 (SPSS). Data were represented in tables and graphs. Continuous quantitative variables e.g. age were expressed as mean \pm SD \& median (range). Categorical qualitative variables were expressed as absolute frequencies (number) \& relative frequencies (percentage). Independent student's T test was used to compare between two groups of normally distributed data. Paired t test was used to compare between two groups before and after therapy. Categorical data were compared using Chi square $\mathrm{t}$ tests. Suitable statistical tests of significance were used after checked for normality. The results were considered statistically significant when the significant probability was equal or less than $0.05(\mathrm{P} \leq 0.05)$. P-value $<0.001$ was considered highly statistically significant (HS), and Pvalue $>0.05$ was considered statistically insignificant (NS).

\section{RESULTS}

This table showed that the mean age of the studied cardiac group was $3.39 \pm 1.17$ years old, with a range from 1 to 5 years old. Half of the studied group were males, and $50 \%$ were females. Age of control group ranged from 2- 6 years old, with no statistically significant difference between both groups regarding age and sex (Table 1).

Table (2) showed that the mean weight of the studied children was $14.04 \pm 2.12 \mathrm{~kg}$. About $1 / 3$ of the studied group had atrial septal defect (ASD) (30\%), while $1 / 4$ of them had Fallot tetralogy (25\%), and only $15 \%$ of them had VSD, subaortic membrane and PM + VSD.

Table (3) showed that the mean pre-operative creatinine value was $0.8 \pm 0.15 \mathrm{mg} / \mathrm{dl}$, with a range from $0.22-0.9 \mathrm{mg} / \mathrm{dl}$. The mean pre-operative hemoglobin level among the studied patients was $12.33 \pm 1.25 \mathrm{gm} / \mathrm{dl}$, with a range from $(11-16 \mathrm{gm} / \mathrm{dl})$.

Table (4) showed that the mean $6 \mathrm{hrs}$ postoperative creatinine was $0.85 \pm 0.16 \mathrm{mg} / \mathrm{dl}$, with a range from $0.24-1 \mathrm{mg} / \mathrm{dl}$. The mean $6 \mathrm{hrs}$ postoperative hemoglobin level among the studied patients was $10.95 \pm 0.86 \mathrm{gm} / \mathrm{dl}$, with a range from 10-13.5. In addition, the mean of $24 \mathrm{hrs}$ postoperative creatinine level was $1.14 \pm 0.27 \mathrm{mg} / \mathrm{dl}$, with a range from 0.75 $1.6 \mathrm{mg} / \mathrm{dl}$. The $24 \mathrm{hrs}$ postoperative mean value of hemoglobin level among the studied patients was 11.5 $\pm 1.57 \mathrm{gm} / \mathrm{dl}$, with a range from $(8-14 \mathrm{gm} / \mathrm{dl})$.

Table (5) showed that the mean creatinine level was significantly increased by $6.25 \%$ and $42.5 \%$ after $6 \mathrm{hrs}$ and 24 hours postoperative respectively.

Table (6) showed that cardiopulmonary bypass time ranged from (13-65 min) and its mean value was $31.10 \pm 16.47 \mathrm{~min}$. In addition, the mean of ischemic time was $17.55 \pm 14.17 \mathrm{~min}$, with a range from 7-55 $\min$.

Table (7) and figure (1) show that about $1 / 3$ of the studied patients $(30 \%)$ developed acute kidney injury and needed kidney dialysis. Figure (1) showed that $70 \%$ of the studied cardiac children had no acute kidney injury, 15\% developed AKI stage 1 and 15\% developed stage 2 AKI. 
Table (1): Demographic data of the studied children $(\mathrm{N}=40)$

\begin{tabular}{|c|c|c|c|c|c|c|}
\hline \multirow[t]{2}{*}{ Demographic data } & \multicolumn{2}{|c|}{$\begin{array}{c}\text { Cases } \\
\text { children }(\mathrm{N}=20)\end{array}$} & \multicolumn{2}{|c|}{ Control $(\mathrm{N}=20)$} & \multirow[t]{2}{*}{ est } & \multirow[t]{2}{*}{ value } \\
\hline & No. & $\%$ & No. & $\%$ & & \\
\hline \multicolumn{7}{|l|}{ Age (years) } \\
\hline Mean \pm SD & \multicolumn{2}{|c|}{$3.39 \pm 1.17$} & \multicolumn{2}{|c|}{$3.53 \pm 1.06$} & \multirow[t]{2}{*}{193.00} & \multirow[t]{2}{*}{$0.858(\mathrm{NS})$} \\
\hline Median (Range) & \multicolumn{2}{|c|}{$3.65(1.0-5)$} & \multicolumn{2}{|c|}{$3.5(2-6)$} & & \\
\hline \multicolumn{7}{|l|}{ Sex } \\
\hline Male & 10 & 50.0 & 8 & 40.0 & \multirow[t]{2}{*}{0.404} & \multirow[t]{2}{*}{$0.751(\mathrm{NS})$} \\
\hline Female & 10 & 50.0 & 12 & 60.0 & & \\
\hline
\end{tabular}

Chi-square test Mann-Whitney test $P$ value $<0.05$ is significant

NS: Non significant

Table (2): Present history and clinical picture of the studied children.

\begin{tabular}{|l|c|c|}
\hline \multirow{2}{*}{ Item } & \multicolumn{2}{|c|}{ Studied children (N=20) } \\
\cline { 2 - 3 } & \multicolumn{2}{|c|}{ No. } \\
\hline Weight (Kg) & \multicolumn{2}{|c|}{$14.04 \pm 2.12$} \\
\hline Mean \pm SD & \multicolumn{2}{|c|}{$13.5(10-18)$} \\
\hline Median (Range) & \multicolumn{2}{|c|}{} \\
\hline Cardiac defect & 6 & 30.0 \\
\hline ASD & 3 & 15.0 \\
\hline VSD & 5 & 25.0 \\
\hline Fallot tetralogy & 3 & 15.0 \\
\hline PM + VSD & 3 & 15.0 \\
\hline Subaortic membrane & \multicolumn{2}{|c|}{} \\
\hline
\end{tabular}

Table (3): Preoperative characteristics among the studied cardiac children.

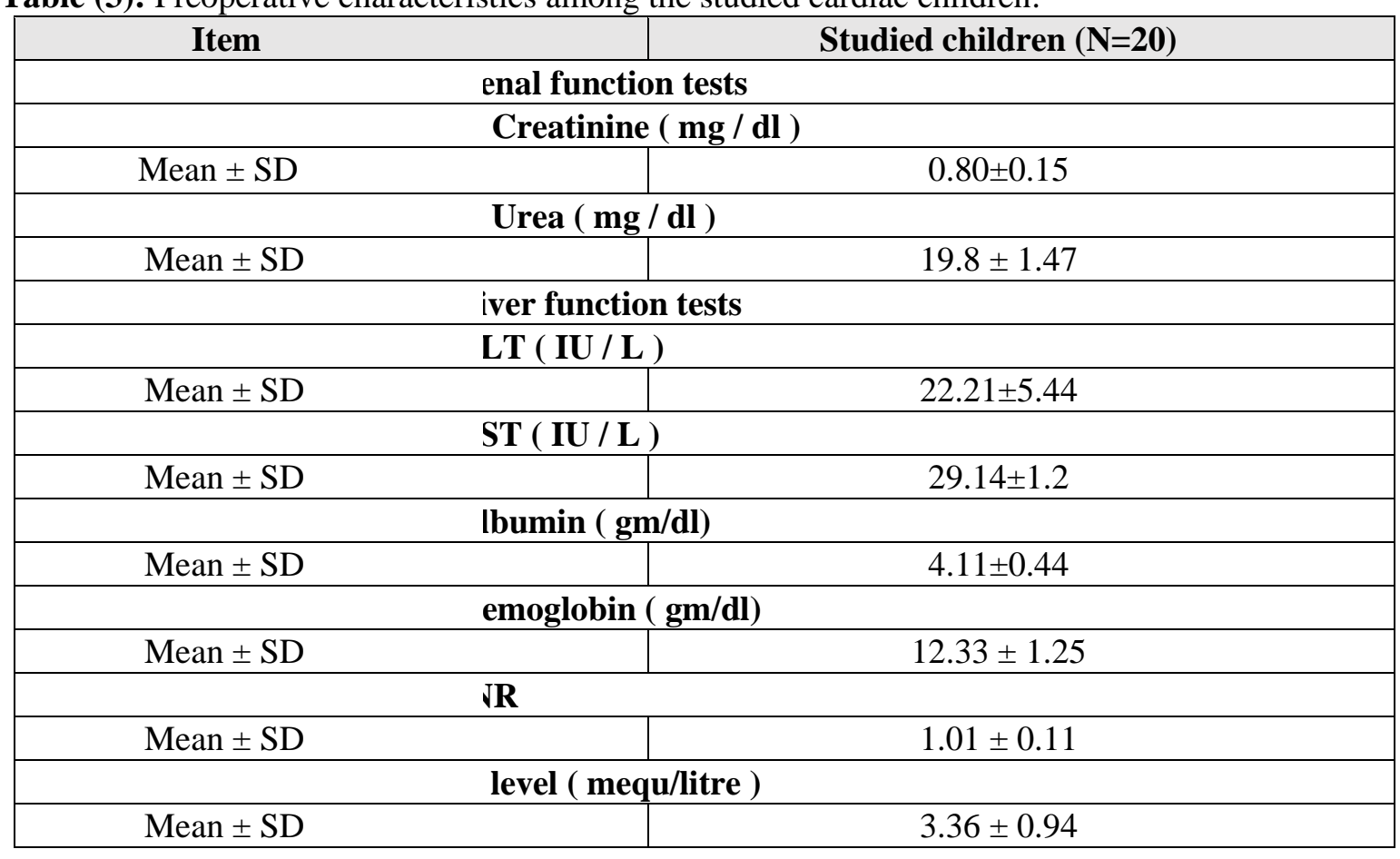


Table (4): Post-operative characteristics after 6 and 24 hours among the studied cases

\begin{tabular}{|c|c|c|c|}
\hline \multicolumn{2}{|c|}{ hrs. Postop. CCC } & \multicolumn{2}{|c|}{24 hrs. Postop. CCC } \\
\hline ariable & $\begin{array}{l}\text { Studied children } \\
\qquad(\mathrm{N}=\mathbf{2 0})\end{array}$ & variable & $\begin{array}{c}\text { Studied children } \\
(\mathbf{N}=\mathbf{2 0})\end{array}$ \\
\hline \multicolumn{4}{|c|}{ Renal function tests } \\
\hline \multicolumn{4}{|c|}{ S. Creatinine ( $\mathrm{mg} / \mathrm{dl}$ ) } \\
\hline ean \pm SD & $0.85 \pm 0.16$ & ean \pm SD & $1.14 \pm 0.27$ \\
\hline \multicolumn{4}{|c|}{ S. Urea ( mg / dl ) } \\
\hline ean \pm SD & $22.7 \pm 3.65$ & ean \pm SD & $31.9 \pm 1.12$ \\
\hline \multicolumn{4}{|c|}{ Liver function tests } \\
\hline \multicolumn{4}{|c|}{ LT ( IU / L ) } \\
\hline ean \pm SD & $74.16 \pm 4.64$ & ean \pm SD & $11.24 \pm 41.3$ \\
\hline \multicolumn{4}{|c|}{ ST ( IU / L ) } \\
\hline ean \pm SD & $119.59 \pm 6.5$ & ean \pm SD & $95.39 \pm 8.8$ \\
\hline \multicolumn{4}{|c|}{ Albumin ( gm / dl ) } \\
\hline ean \pm SD & $3.27 \pm 0.1$ & ean \pm SD & $8.15 \pm 1.45$ \\
\hline \multicolumn{4}{|c|}{ Hemoglobin ( gm/dl) } \\
\hline ean $\pm \mathrm{SD}$ & $10.95 \pm 0.86$ & ean \pm SD & $11.5 \pm 1.57$ \\
\hline \multicolumn{4}{|c|}{ INR } \\
\hline ean \pm SD & $1.29 \pm 0.22$ & ean \pm SD & $1.38 \pm 0.09$ \\
\hline \multicolumn{4}{|c|}{ K level ( mequ/litre ) } \\
\hline ean $\pm S D$ & $4.17 \pm 1.41$ & ean \pm SD & $3.9 \pm 1.32$ \\
\hline
\end{tabular}

Table (5): Percentage of change in renal function test among the studied cardiac patients

\begin{tabular}{|c|c|c|c|c|c|}
\hline $\begin{array}{c}\text { Renal function } \\
\text { test }\end{array}$ & Preoperative & $\begin{array}{c}6 \text { hours } \\
\text { Postoperative }\end{array}$ & $\begin{array}{c}24 \text { hours } \\
\text { Postoperative }\end{array}$ & \begin{tabular}{|l|}
$\%$ of change \\
Pre- post 1
\end{tabular} & $\begin{array}{l}\% \text { of change } \\
\text { Pre-post } 2\end{array}$ \\
\hline \multicolumn{6}{|l|}{ S. Creatinine } \\
\hline Mean \pm SD & $0.80 \pm 0.15$ & $0.85 \pm 0.16$ & $1.14 \pm 0.27$ & \multirow[t]{2}{*}{$\uparrow 6.25 \%$} & \multirow[t]{2}{*}{$\uparrow 42.5 \%$} \\
\hline Median (Range) & $0.80(0.22-0.9)$ & $0.87(0.24-1)$ & $1.0(0.75-1.6)$ & & \\
\hline tp-value 1 & \multicolumn{3}{|c|}{$0.000^{*}$} & & \\
\hline \multirow[t]{2}{*}{ \#p-value 2} & Ref & $0.001 *$ & $0.001 *$ & & \\
\hline & ------- & Ref & $0.003 *$ & & \\
\hline
\end{tabular}

† P1: p-value of Freidman \# P2: p-value of Wilcoxon signed rank test $\quad$ Significant: P-value $<0.05$

Table (6): Operative characteristic among the studied cardiac children

\begin{tabular}{|l|c|}
\hline \multicolumn{1}{|c|}{ Item } & Studied children $(\mathbf{N}=20)$ \\
\hline Cardiopulmonary bypass time (min) & $31.10 \pm 16.47$ \\
\hline Mean \pm SD & \\
\hline Ischemic time (min) & $17.55 \pm 14.17$ \\
\hline Mean \pm SD &
\end{tabular}

Table (7): Acute kidney injury among the studied cardiac children

\begin{tabular}{|l|c|c|}
\hline \multirow{2}{*}{ Item } & \multicolumn{2}{c|}{ Studied children (N=20) } \\
\cline { 2 - 3 } & No. & \% \\
\hline Stage of acute kidney injury & \multicolumn{2}{|c|}{} \\
\hline$\square$ No & 14 & 70.0 \\
\hline$\square$ Stage 1 & 3 & 15.0 \\
\hline$\square$ Stage 2 & 3 & 15.0 \\
\hline Dialysis & & \\
\hline$\square$ No & 14 & 70.0 \\
\hline$\square$ yes & 6 & 30.0 \\
\hline
\end{tabular}




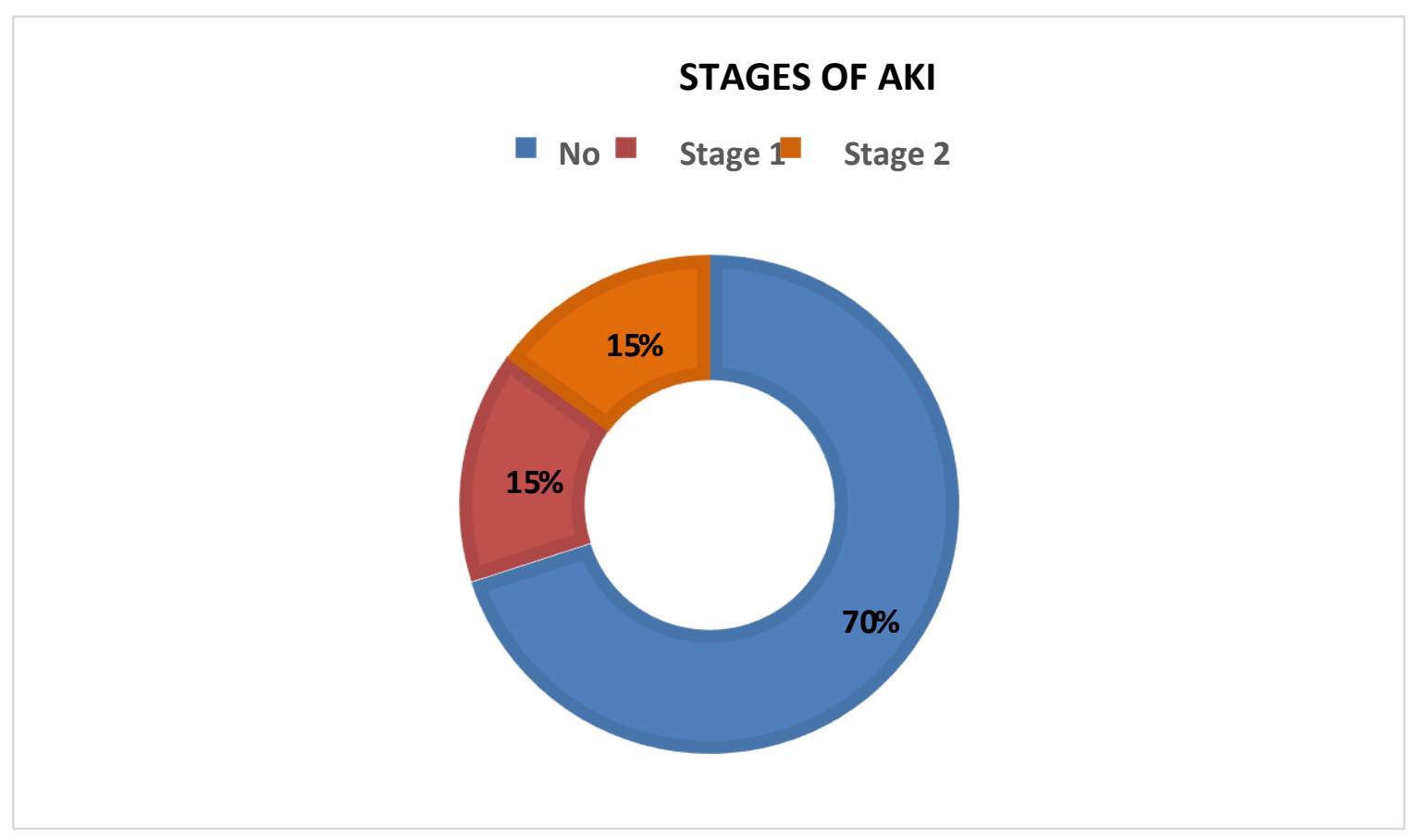

Figure (1): Stage of acute kidney injury among the studied cardiac children

\section{DISCUSSION}

The mean age of our patients was $3.39 \pm 1.17$ years with a range from 1 to 5 years. $50 \%$ were males and $50 \%$ were females with no statistically significant difference between patients' group and control group regarding age and sex. about $1 / 3$ of the studied group had ASD (30\%), while $1 / 4$ of them had Fallot tetralogy $(25 \%)$, and only $15 \%$ of them had VSD, subaortic membrane and PM + VSD. Similarly, Krawczeski et $\boldsymbol{a l} .{ }^{\left({ }^{(6)}\right.}$ reported in their study on children with congenital heart disease, that the mean age was $1.5 \pm 2.9$ years in patients who developed AKI and $4.4 \pm 5.4$ years in patients without AKI with highly statistically significant difference $(p<0.0001)$. In addition, they reported that there was no statistically significant difference regarding sex distribution among their studied groups. In addition, Zappitelli et al. ${ }^{(5)}$ reported in their study on pediatric population with cardiac surgery that the mean age of the patients was $3.8 \pm 4.5$ years and there was no significant difference regarding sex distribution $(55 \%$ of study population were males).

The mean weight of the studied children was $14.04 \pm 2.12 \mathrm{~kg}$, which is below $50^{\text {th }}$ centile. This underweight is probably attributed to chronicity of the disease, bad general condition and malnourishment of the children as a result from frequent hospital admission. In the contrary, Zappitelli et al. ${ }^{(5)}$ reported that the mean weight of their study population was $16.4 \pm 17.3 \mathrm{~kg}$ (above $50^{\text {th }}$ centile), which is higher than our study and this could be explained by different race of study population and large sample size (228 child).

AKI was defined as the development of at least stage (1) AKI defined by AKI Network (AKIN) as at least $\mathrm{a} \geq 50 \%$ rise or $\mathrm{a} \geq 0.3 \mathrm{mg} / \mathrm{dl}$ rise from baseline serum creatinine during hospitalization after cardiac surgery. Stage (2) AKI was defined as a doubling in serum creatinine from baseline. Stage (3) AKI was defined as a tripling in serum creatinine from baseline or receiving acute dialysis during the hospital stay ${ }^{(7)}$. Stage (1) is at least a $50 \%$ SCr rise from baseline within 7 days or a $0.3-\mathrm{mg} / \mathrm{dL}$ rise within 48 hours, stage (2) is SCr doubling, and stage (3) is SCr tripling requiring dialysis or an eGFR of less than 35 $\mathrm{mL} / \mathrm{min} / 1.73 \mathrm{~m}^{2}$ at any time.

The Cys C-AKI was defined by applying the Kidney Disease:

Improving Global Outcomes definition but using Cys $\mathrm{C}$ change instead of $\mathrm{SCr}$ changes similar to what has been done by others.

According to previous definition, serum creatinine rise $\geq 0.3 \mathrm{mg} / \mathrm{dl}$ from baseline at 24-hour postoperative denoted stage (1) AKI, while serum cystatin $\mathrm{C}$ increased by $80 \%$ at 6 hours post-operative. Regarding stages of acute kidney injury, our results revealed that $70 \%$ of the patients had no acute kidney injury, 15\% developed AKI stage (1) and 15\% developed stage (2) AKI. In addition, all patients with AKI needed dialysis. On the contrary, Greenberg $\boldsymbol{e t}$ al. ${ }^{(8)}$ reported that only $3(11 \%)$ of patients with AKI in progression needed dialysis, versus $0 \%$ of patients 
with no progressive AKI with significant difference $(\mathrm{p}=0.001)$.

Regarding serum creatinine level in our study, at 6 and 24 hours postoperatively, our results revealed that the mean serum creatinine level was $0.85 \pm 0.16$ and $1.14 \pm 0.27 \mathrm{mg} / \mathrm{dl}$ with percentage of increase $6.25 \%$ and $42.5 \%$ from baseline preoperative level respectively with highly statistically significant difference $(\mathrm{P}=0.000)$. Similarly, Zappitelli et al. ${ }^{(5)}$ reported that First postoperative percent $\mathrm{SCr}$ change was also independently associated with the development of stage (1) AKI, but not of stage (2) AKI. When percent $\mathrm{SCr}$ change was added to the clinical variable predictive model, AUC was increased by $\sim 5 \%$ for predicting future stage (1) AKI $(\mathrm{P}<0.01)$, but by only $\sim 2 \%$ for predicting stage (2) AKI (P = 0.2 ). When time after surgery (hours) of first postoperative blood sample was controlled for in all analyses, ORs were nearly identical except confidence intervals (CIs) were wider.

Our results revealed that the mean Cardiopulmonary bypass time was $31.10 \pm 16.47 \mathrm{~min}$ with a range from 13-65 min. The mean ischemic time was $17.55 \pm 14.17 \mathrm{~min}$, with a range from 7-55 min. In addition, the mean hospital stay was $2.60 \pm 1.5$ days ranged from 1-8 days.

\section{CONCLUSION}

Present study identified that high percentage of pediatric patients with congenital heart disease following open-heart surgery developed acute kidney injury.

\section{REFERENCES}

1. Rizvi S, Mustafa G, Kundi A et al. (2015): Prevalence of Congenital Heart Disease in Rural Communities of Pakistan. J Ayub Med Coll Abbottabad, 27 (1): 124-27.

2. Pezzella A (2017): Cardiothoracic Surgery in Developing Countries. Annals of Thoracic Surgery, 104 (1): 373-74.

3. Smitha R, Karat S, Narayanappa D et al. (2006): Original Communication Prevalence of Congenital Heart Diseases in Mysore. Indian Journal of Human Genetics, 12 (1): 11-16.

4. Wanni K, Shahzad N, Ashraf M et al. (2014): Prevalence and spectrum of congenital heart diseases in children. Heart India, 2: 76-9.

5. Zappitelli M, Krawczeski C, Devarajan $P$ et al. (2011): Early postoperative serum cystatin $\mathrm{C}$ predicts severe acute kidney injury following pediatric cardiac surgery. Kidney Int., 80 (6): 655-62.

6. Krawczeski C, Rene G, Kathman T et al. (2010): Griffiths, and Prasad Devarajan. Serum Cystatin C Is an Early Predictive Biomarker of Acute Kidney Injury after Pediatric Cardiopulmonary Bypass. Clin J Am Soc Nephrol., 5: 1552-1557.

7. Mehta R, Kellum J, Shah S et al. (2007): Acute Kidney Injury Network: Acute kidney injury network: Report of an initiative to improve outcomes in acute kidney injury. Crit Care, 11: 31-36.

8. Greenberg J, Zappitelli M, Jia Y et al. (2018): Biomarkers of AKI Progression after Pediatric Cardiac Surgery. J Am Soc Nephrol., 29 (5): 1549-1556. 